\title{
Acquired Factor V Inhibitors in a Patient with End-stage Renal Disease
}

\author{
Atsushi Kitazawa, Hideo Misawa, Katsuhiro Nagahori, Ryo Koda, Atsunori Yoshino, \\ Shinya Kawamoto and Tetsuro Takeda
}

\begin{abstract}
We report a case of acquired factor $\mathrm{V}$ inhibitors (AFVIs) in a patient with end-stage renal disease receiving warfarin therapy for atrial fibrillation. A 72-year-old Japanese man was admitted to our hospital complaining of tarry stools and abdominal pain. The laboratory findings revealed eosinophilia (52.1\%), prolonged activated partial thromboplastin time (APTT) (98 s), PT (84 s), a factor V (FV) activity of $<3 \%$, and an FV inhibitor level of 6 Bethesda units $/ \mathrm{mL}$. After administration of prednisolone was started, his coagulation findings improved. However, his renal failure progressed, and he ultimately required chronic hemodialysis. This is the first case of AFVIs in a patient starting hemodialysis for end-stage renal disease.
\end{abstract}

Key words: factor V inhibitor, eosinophilia, warfarin

(Intern Med 55: 3505-3509, 2016)

(DOI: 10.2169/internalmedicine.55.7369)

\section{Introduction}

Acquired coagulation factor deficiency is a rare autoimmune disease in which inhibitory autoantibodies to coagulation factors are produced. These antibodies reduce the activity of coagulation factors, leading to a bleeding tendency. Most autoantibodies are to factor VIII (F8), referred to as acquired hemophilia $\mathrm{A}$, and occur at a frequency of 1:100 million people. In Japan, the incidence of acquired factor $\mathrm{V}$ inhibitors (AFVIs) has been reported as 1:50 relative to acquired hemophilia A (1).

\section{Case Report}

A 72-year-old man with end-stage renal disease (resulting from nephrosclerosis) was admitted to our hospital with fatigue, abdominal pain, and tarry stools in the middle of September. His medical history included chronic atrial fibrillation (AF), congestive heart failure with massive aortic regurgitation (AR), and peptic ulcer disease. He was taking the following chronic medications: warfarin, carvedilol, amlodipine, olmesartan, febuxostat, furosemide, and lansoprazole.
A physical examination at the time of admission revealed pale-colored conjunctivae and epigastric tenderness. The laboratory findings on admission are summarized in Table 1. In brief, the eosinophil count was markedly increased $(52.1 \%)$, and the hemoglobin level was reduced $(9.7 \mathrm{~g} / \mathrm{dL})$. The prothrombin time-international normalized ratio (PTINR) was increased to 7.27 , but the D-dimer value $(0.45 \mu \mathrm{g} /$ $\mathrm{mL})$ was within the normal range. A chest $\mathrm{X}$-ray showed cardiomegaly, with a cardiothoracic ratio of $66 \%$ (Fig. 1). A computed tomography (CT) scan of his abdomen showed bilateral renal atrophy and a mass, $38 \mathrm{~mm}$ in diameter, in the right kidney (Fig. 2).

The patient's clinical course is illustrated in Fig. 3. Initially, warfarin toxicity was suspected. Thus, the warfarin was stopped, and vitamin $\mathrm{K}$ was administered intravenously, with a subsequent temporary improvement in his PT values. Although upper and lower gastrointestinal tract endoscopy was performed, no obvious source of bleeding was identified. However, on Day 14 of admission, a CT scan of the chest showed bilateral massive infiltrative shadows in the right middle and lower lobes of the lung, suggesting an alveolar hemorrhage. On Day 15, the PT-INR value had increased to 5.76, and the activated partial thromboplastin time (APTT) was markedly prolonged (>180 s). His findings

Nephrology, Dokkyo Medical University Koshigaya Hospital, Japan

Received for publication March 7, 2016; Accepted for publication April 20, 2016

Correspondence to Dr. Atsushi Kitazawa, atsukitaaq@gmail.com 
Table 1. Laboratory Findings on Admission.

\begin{tabular}{|c|c|c|c|c|c|c|}
\hline \multicolumn{2}{|l|}{ Peripheral blood } & \multicolumn{2}{|c|}{ Blood chemistry } & \multicolumn{3}{|c|}{ Immuno-serological findings } \\
\hline WBC & $5,600 / \mu \mathrm{L}$ & $\mathrm{TP}$ & $7.9 \mathrm{~g} / \mathrm{dL}$ & $\operatorname{IgG}$ & 3,049 & $\mathrm{mg} / \mathrm{dL}$ \\
\hline (neutro) & $33.3 \%$ & Alb & $3.49 \mathrm{~g} / \mathrm{dL}$ & $\operatorname{Ig} A$ & 409 & $\mathrm{mg} / \mathrm{dL}$ \\
\hline (lym) & $8.3 \%$ & T-bil & $0.53 \mathrm{mg} / \mathrm{dL}$ & $\operatorname{IgM}$ & 83 & $\mathrm{mg} / \mathrm{dL}$ \\
\hline (mono) & $4.7 \%$ & AST & $13 \mathrm{IU} / \mathrm{L}$ & $\operatorname{IgE}$ & 2,840 & $\mathrm{IU} / \mathrm{mL}$ \\
\hline (eosino) & $52.1 \%$ & ALT & $12 \mathrm{IU} / \mathrm{L}$ & IgG4 & 142 & $\mathrm{mg} / \mathrm{dL}$ \\
\hline $\mathrm{RBC}$ & $323 \times 10^{4} / \mu \mathrm{L}$ & $\mathrm{LDH}$ & $260 \mathrm{IU} / \mathrm{L}$ & CH50 & 33.3 & $\mathrm{IU} / \mathrm{mL}$ \\
\hline $\mathrm{Hb}$ & $9.7 \mathrm{~g} / \mathrm{dL}$ & ALP & $215 \mathrm{IU} / \mathrm{L}$ & $\mathrm{C} 3$ & 63 & $\mathrm{mg} / \mathrm{dL}$ \\
\hline $\mathrm{Ht}$ & $30.1 \%$ & $\gamma$-GTP & $25 \mathrm{IU} / \mathrm{L}$ & $\mathrm{C} 4$ & 13.4 & $\mathrm{mg} / \mathrm{dL}$ \\
\hline Plt & $10.8 \times 10^{4} / \mu \mathrm{L}$ & Ch-E & $163 \mathrm{IU} / \mathrm{L}$ & ANA & $\times 40$ & \\
\hline Coagulation test & & Ferritin & $233 \mathrm{ng} / \mathrm{mL}$ & ds-DNA IgG & $\times 2.8$ & \\
\hline PT(S) & $84.6 \mathrm{sec}$ & BUN & $79 \mathrm{mg} / \mathrm{dL}$ & MPO-ANCA & $<1.0$ & $\mathrm{IU} / \mathrm{mL}$ \\
\hline PT(\%) & $9.0 \%$ & $\mathrm{Cr}$ & $7.1 \mathrm{mg} / \mathrm{dL}$ & PR3-ANCA & $<1.0$ & $\mathrm{IU} / \mathrm{mL}$ \\
\hline PT-INR & 7.27 & $\mathrm{Na}$ & $136 \mathrm{mEq} / \mathrm{L}$ & anti-GBM Ab & $<2.0$ & $\mathrm{IU} / \mathrm{mL}$ \\
\hline APTT (day6) & $98.5 \mathrm{sec}$ & $\mathrm{K}$ & $4.8 \mathrm{mEq} / \mathrm{L}$ & anti-SS-A Ab & $<7.0$ & $\mathrm{IU} / \mathrm{mL}$ \\
\hline Fib & $462 \mathrm{mg} / \mathrm{dL}$ & $\mathrm{Cl}$ & $110 \mathrm{mEq} / \mathrm{L}$ & anti-SS-B Ab & $<7.0$ & $\mathrm{IU} / \mathrm{mL}$ \\
\hline FDP & $4.1 \mathrm{ng} / \mathrm{mL}$ & $\mathrm{Ca}$ & $8.2 \mathrm{mg} / \mathrm{dL}$ & $\mathrm{RF}$ & $<3$ & $\mathrm{IU} / \mathrm{mL}$ \\
\hline D-dimer & $0.45 \mu \mathrm{g} / \mathrm{mL}$ & IP & $4.1 \mathrm{mg} / \mathrm{dL}$ & anti-CCP Ab & 0.6 & $\mathrm{IU} / \mathrm{mL}$ \\
\hline Tumor marker & & UA & $6.0 \mathrm{mg} / \mathrm{dL}$ & sIL-2R & 5,780 & $\mathrm{IU} / \mathrm{mL}$ \\
\hline CEA & $3.3 \mathrm{ng} / \mathrm{mL}$ & $\mathrm{CK}$ & 48 IU/L & HBs Ag & $(-)$ & \\
\hline CA19-9 & $19.8 \mathrm{IU} / \mathrm{mL}$ & CRP & $0.81 \mathrm{mg} / \mathrm{dL}$ & $\mathrm{HCV} \mathrm{Ab}$ & $(-)$ & \\
\hline PSA & $0.407 \mathrm{ng} / \mathrm{mL}$ & & & T-spot & $(-)$ & \\
\hline
\end{tabular}

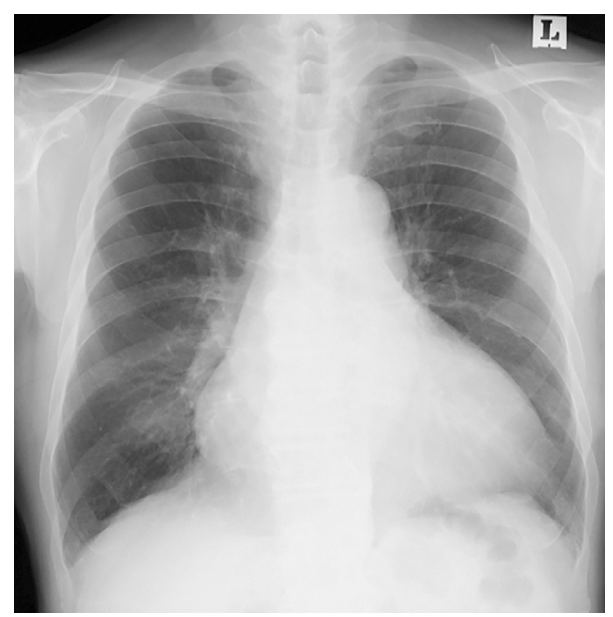

Figure 1. A chest X-ray on admission showed cardiomegaly, with a cardiothoracic ratio of $66 \%$.

for lupus anticoagulant diluted Russell's viper venom time (dRVVT) were positive (>1.33, normal range: $0-1.3 \mathrm{~s}$ ), and his level of anti- $\beta 2$-glycoprotein 1 (aB2GP1) IgG antibody was $3.2 \mathrm{U} / \mathrm{mL}$ (normal range: $<3 \mathrm{U} / \mathrm{mL}$ ) and anti-cardiolipin (aCL) $\mathrm{IgG}$ antibody was $38 \mathrm{U} / \mathrm{mL}$ (normal range: $<10 \mathrm{U} /$ $\mathrm{mL}$ ). A plasma cross-mixing test was then performed and revealed no factor deficiency, but suggested a delayed-type inhibitor pattern (Fig. 4). We suspected acquired hemophilia and carried out tests to detect the coagulation factor activity and inhibitor presence (Table 2). The activity of factor $\mathrm{V}$ $(\mathrm{FV})$ was quite low $(<3 \%)$. The specific inhibitor for $\mathrm{FV}$ was present, with a titer of 6 Bethesda units $/ \mathrm{mL}(\mathrm{BU} / \mathrm{mL})$. Thus, prednisolone was initiated, starting at a dose of 60 $\mathrm{mg} /$ day $(1.0 \mathrm{mg} / \mathrm{kg} / \mathrm{day})$. The patient's eosinophilia soon improved. The findings from his coagulation studies improved markedly, but his renal failure progressed with oliguria, and he ultimately required chronic hemodialysis.

By Day 34 of admission, the findings from his coagula-

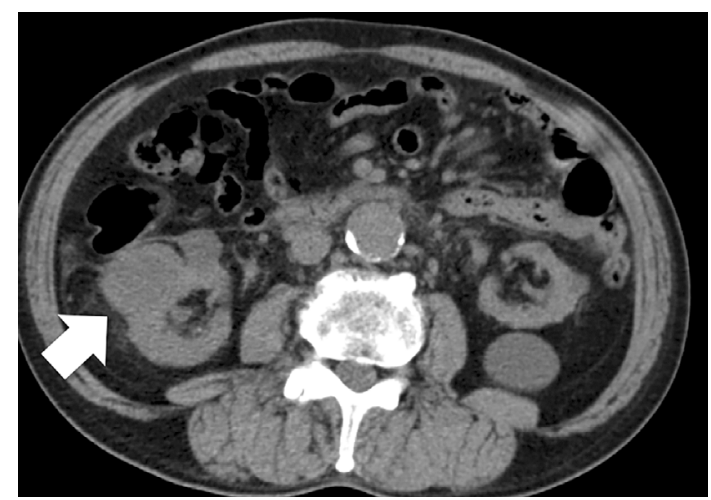

Figure 2. Abdominal computed tomography on admission revealing bilateral renal atrophy and a mass, $38 \mathrm{~mm}$ in diameter, in the right kidney.

tion studies had normalized (PT-INR: 1.22, APTT: $30.1 \mathrm{~s}$ ), so an arteriovenous fistula was surgically created for ongoing hemodialysis. On Day 40, the FV activity increased to $61 \%$, and the test for FV inhibitors was negative. Prednisolone was thus tapered to $50 \mathrm{mg} /$ day. On Day 42 , capsule endoscopy revealed a wide area of redness and erosion in the small intestine. This was considered to be the source of the bleeding that resulted in the tarry stool and anemia.

The patient had experienced pain in both upper limbs on Day 15 and thereafter had some numbness in the upper and lower limbs. A nerve conduction test showed multiple mononeuropathies. Once prednisolone was started, the upper limb pain improved, although the numbness remained. The prednisolone dosage was gradually reduced. The levels of the coagulation markers remained stable, and the FV inhibitors remained undetectable. The patient was discharged after 91 days in the hospital. The prednisolone dosage was tapered to $7.5 \mathrm{mg} /$ day. One year later, the prednisolone had 


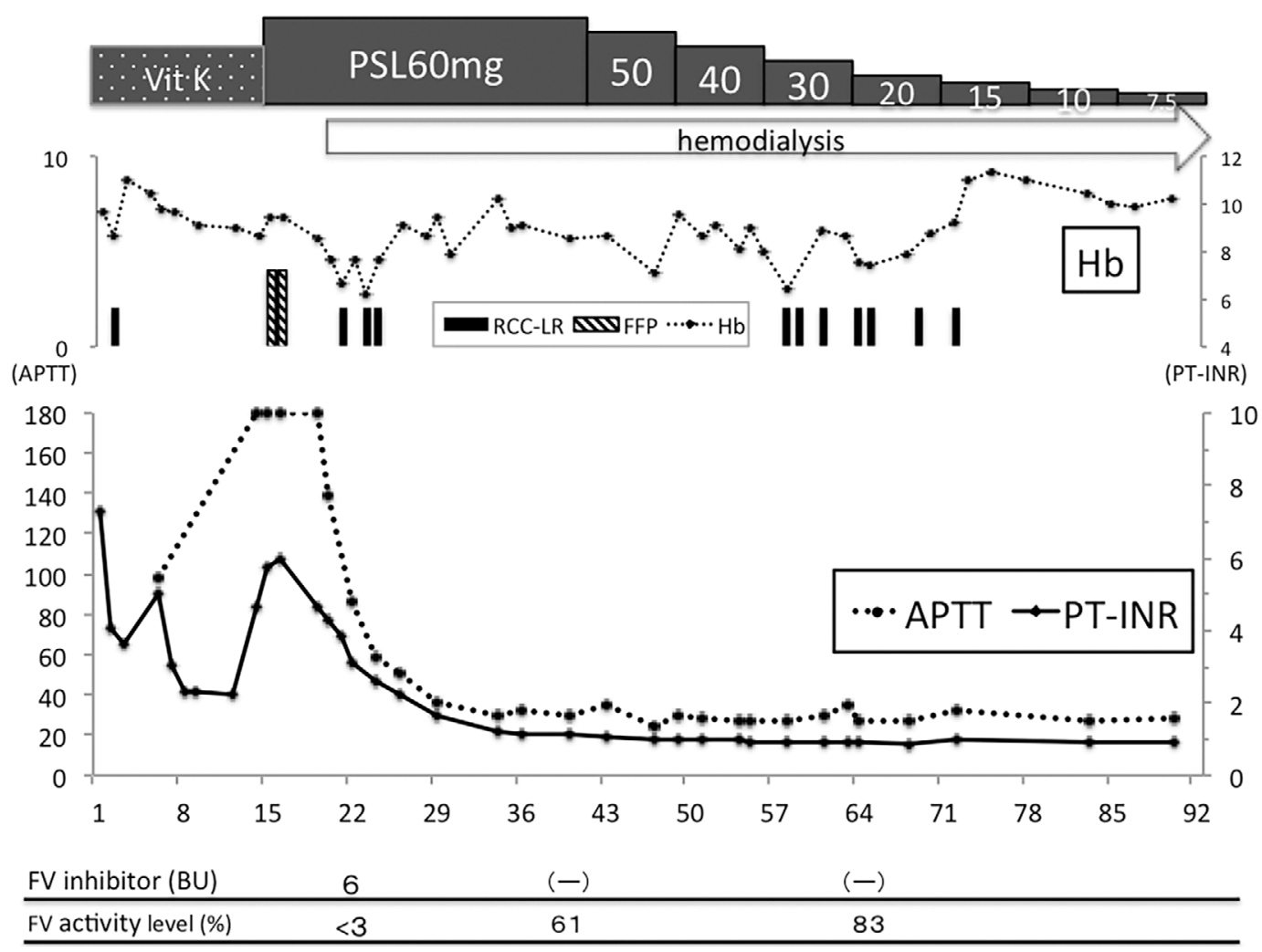

Figure 3. Clinical course. Horizontal axis: hospital days, APTT: activated partial thromboplastin time (s), PT-INR: international normalized ratio of prothrombin time, Hb: hemoglobin (g/dL), Vit K: Vitamin K (Menatetrenone), PSL: prednisolone (mg/day), FFP: Fresh frozen plasma, RCC-LR: red cells concentrates-leukocytes reduced

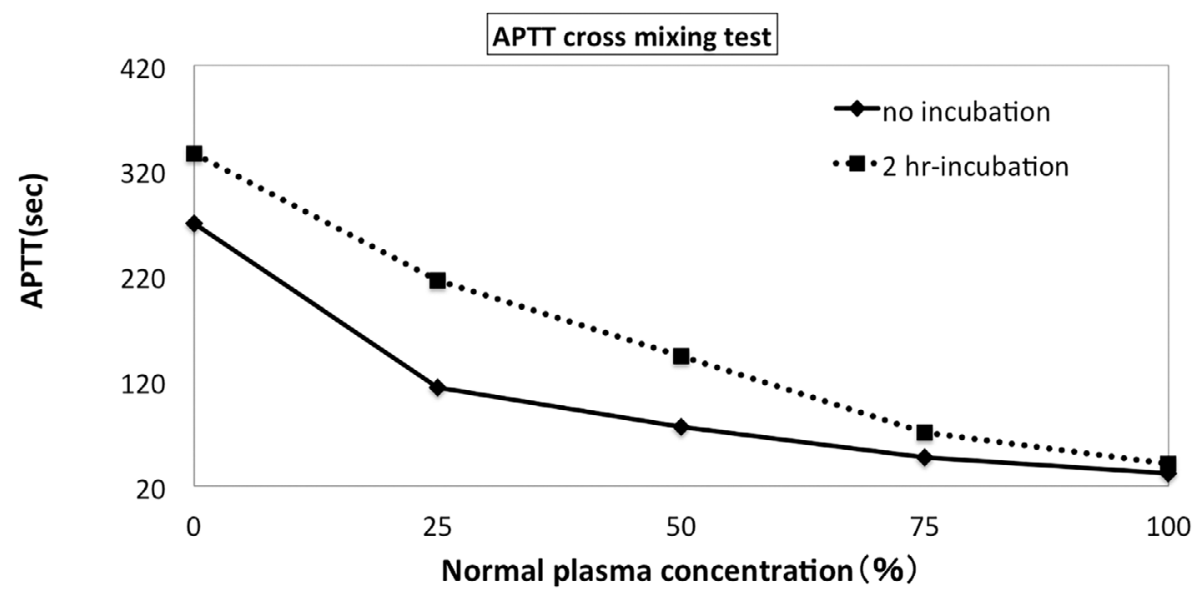

Figure 4. Cross-mixing test. Plasma from the patient and normal were mixed at various rations after incubation for $2 \mathrm{~h}$ at $37^{\circ} \mathrm{C}$. It demonstrated no factor deficiency but suggested a delayed-type inhibitor pattern.

Table 2. Coagulation Factor Assay.

\begin{tabular}{ccc}
\hline & activity & inhibitor \\
Factor II & $46 \%(75-135)$ & negative \\
Factor V & $<3 \%(70-135)$ & $6 \mathrm{BU} / \mathrm{mL}$ \\
Factor VII & $101 \%(75-140)$ & no data \\
Factor VIII & $63 \%(60-150)$ & negative \\
Factor IX & $84 \%(70-130)$ & negative \\
Factor X & $67 \%(0-50)$ & negative \\
Factor XI & $56 \%(75-145)$ & no data \\
Factor XII & $104 \%(50-150)$ & no data \\
\hline
\end{tabular}

been tapered to $1 \mathrm{mg} /$ day, the FV inhibitors remained undetectable, and he continued hemodialysis without complications.

Discussion

AFVI was first reported by Hörder et al. in 1955. According to a systematic review by Franchini, by 2010, there had been 159 reported cases, 70 of which were associated with 
previous exposure to topical bovine thrombin. In the remainder of cases, the underlying causes were reported to be autoimmune $(13 \%)$, tumor-associated $(22 \%)$, and antibacterial drug-induced, notably $\beta$-lactam antibiotics (42\%); $21 \%$ were classified as idiopathic (2). In the present case, several causes were considered, including tumor-associated (renal cell carcinoma was suspected, given the kidney mass identified on CT), warfarin, eosinophilia-related, and autoimmune (aCL-positive).

More than one year later, the kidney mass had neither increased in size nor metastasized, and the AFVIs did not recur. Given that we were unable to find any previous reports of renal cell carcinoma as a cause of AFVIs, we believe the renal mass was unlikely to be the underlying cause of the AFVI in the present patient.

Four cases of AFVI related to warfarin therapy have been reported, but none identified the cause (3-6). In the present case, despite a two-week interval between the withdrawal of warfarin and the initiation of prednisolone, the coagulation abnormalities and eosinophilia did not improve spontaneously on withdrawal of the warfarin. In addition, 8 days before warfarin was started, the proportion of eosinophils had already increased to $15 \%$. Thus, whether or not warfarin was the underlying cause is unclear.

All three cases of acquired coagulation factor inhibitor associated with eosinophilia had FVIs (7-9). Interestingly, these three cases also suffered from kidney diseases. One case was a maintenance dialysis patient, and the other two had membranous nephropathy, which is caused by immune complex formation in the glomerulus. The present case had bilateral renal atrophy, and from the clinical course, he was considered to have nephrosclerosis, but further details were unclear, as renal biopsy had not been performed. In addition to marked eosinophilia, our patient also was positive for antiphospholipid antibodies (aCL and aB2GP1) and had elevated serum IgG levels and multiple mononeuropathies, suggesting the presence of an immunological disorder. However, the diagnostic criteria for systemic lupus erythematosus, eosinophilic granulomatous vasculitis, and polyarteritis nodosa were not met.

The relationship between renal disease or renal failure and AFVIs is unclear for rare diseases, but some as-yet-unknown immunological mechanism causing eosinophilia might be involved in the production of the FV inhibitors.

The mucosal erosion observed in the present patient was confined to the small intestine and not biopsied. A diagnosis of eosinophilic gastroenteritis was suggested, given the eosinophilia, elevated serum IgG levels, diarrhea, and the wide range of small bowel erosions. Further, the patient's gastrointestinal symptoms (abdominal pain, tarry stool, and diarrhea) resolved with steroid therapy. With the use of capsule endoscopy and double-balloon enteroscopy spreading, reports have begun to appear in the literature of eosinophilic enteritis localized to the small intestine (10-12).

There is no well-established treatment for AFVIs, but immunosuppressive therapy (including corticosteroids and cy- clophosphamide), intravenous immunoglobulins, and plasmapheresis are reported to be effective, similar to the treatment for acquired hemophilia (2). Some reports suggest that rituximab is effective in patients presenting with severely bleeding diathesis (13-16).

The findings from the cross-mixing test provided a clue to the diagnosis in this particular case, prompting us to start treatment with prednisolone, which rapidly improved the patient's coagulation abnormalities. Given that the coagulation factor activity and inhibitor presence take a long time to evaluate, the cross-mixing test is helpful in obtaining an early diagnosis.

Although there have been two reported cases of AFVIs occurring in patients on maintenance hemodialysis $(7,17)$, this is the first case of AFVIs in a patient initiating hemodialysis for end-stage renal disease.

\section{The authors state that they have no Conflict of Interest (COI).}

\section{References}

1. Tamai Y, Takami H. Acquired hemophilia. Nihon Naika Gakkai Zasshi 103: 1622-1630, 2014 (in Japanese).

2. Franchini M, Lippi G. Acquired factor V inhibitors. A systematic review. J Thromb Thrombolysis 31: 449-457, 2011.

3. Nozu T, Mita H, Okumura T. Acquired factor V inhibitor in a patient with a mechanical aortic valve under warfarin therapy. Intern Med 49: 2229-2233, 2010.

4. Gartrell B. Acquired factor V inhibitor complicating warfarin therapy. Am J Hematol 86: 710-712, 2011.

5. Khalafallah A, Grabek J, Hayes R, Mohamed M. Bleeding associated with acquired factor $\mathrm{V}$ inhibitor in a patient on warfarin treated successfully with prednisolone. BMJ Case Reports 6: bcr 2013010018, 2013.

6. Kinjo Y, Yoshimura K, Suzuki T, et al. Development of asymptomatic acquired factor $\mathrm{V}$ inhibitor after the administration of antibiotic. Rinsho Ketsueki 55: 2311-2315, 2014 (in Japanese, Abstract in English).

7. Iino N, Maruyama H, Gejo F. Acquired coagulation abnormality due to factor V inhibitor. Nihon Naika Gakkai Zasshi 92: 32953297, 2002 (in Japanese).

8. Kitamura S, Misawa M, Namba S, et al. Membranous nephropathy with acquired factor V inhibitor: a case report. BMC Research Notes 6: 553, 2013.

9. Takahashi H, Fuse I, Abe T, Yoshino N, Aizawa Y. Acquired factor $\mathrm{V}$ inhibitor complicated by Hashimoto's thyroditis, primary biliary cirrhosis and membranous nephropathy. Blood Coagul Fibrinolysis 14: 87-93, 2003.

10. Matsui T, Murata K, Kaneko M, et al. A case of ensinophilic enteritis successfully observed by capsule endoscopy before and after treatment. Nihon Syoukaki Naisikyou Gakkai Zasshi 55: 33943400, 2013 (in Japanese, Abstract in English).

11. Endo H, Hosono K, Inamori M, et al. Capsule endoscopic evaluation of eosinophilic enteritis before and after treatment. Digestion 83: 134-135, 2011.

12. Okada K, Daimon Y, Iwase T, Mitsufuji S. Novel findings of capsule endoscopy and double-ballon enteroscopy in a case of eosinophilic gastroenteritis. Clin J Gastroenterol 6: 16-19, 2013.

13. Lian EC, Tzakis AG, Andrews D. Response of factor V inhibitor to Rituximab in a patient who receive liver transplantation for primary biliary cirrhosis. Am J Hematol 77: 363-365, 2004.

14. Perdekamp MT, Rubenstein DA, Jesty J, Hultin MB. Platelet fac- 
tor $\mathrm{V}$ supports hemostasis in a patient with an acquired factor $\mathrm{V}$ inhibitor, as shown by prothrombinase and tenase assys. Blood Coagul Fibrinolysis 17: 593-597, 2006.

15. Lebrun A, Leroy-Matheron C, Arlet JB, Bartolucci P, Michel M. Successful treatment with rituximab in a patient with an acquired factor V inhibitor. Am J Hematol 83: 163-164, 2008.

16. Yamada Y, Miyakawa Y, Sawano M, Okano Y. Successful treatment of severe lung hemorrhage caused by acquired factor $\mathrm{V}$ inhibitor with rituximab. Intern Med 53: 1083-1085, 2014.
17. Ishizu M, Kuroiwa M, Tanaka K, Hasegawa Y. Severe hemorrhagic tendency due to factor $\mathrm{V}$ inhibitor in a hemodialysis patient: a case report. Nihon Toseki Igakkai Zasshi 36: 1285-1288, 2003 (in Japanese, Abstract in English).

The Internal Medicine is an Open Access article distributed under the Creative Commons Attribution-NonCommercial-NoDerivatives 4.0 International License. To view the details of this license, please visit (https://creativecommons.org/licenses/ by-nc-nd/4.0/).

(C) 2016 The Japanese Society of Internal Medicine http://www.naika.or.jp/imonline/index.html 